\title{
Accuracy Improvement of the XRD-Rietveld Method for the Quantification of Crystalline Phases in Iron Sintered Ores through the Correction of Micro-absorption Effects
}

\author{
Takayuki HARANO, ${ }^{1,2) *}$ Yu NEMOTO, ${ }^{3)}$ Reiko MURAO ${ }^{1)}$ and Masao KIMURA ${ }^{2,4)}$ \\ 1) Advanced Technology Research Laboratories, Research \& Development, Nippon Steel Corporation, 20-1 Shintomi, Futtsu, \\ Chiba, 293-8511 Japan. \\ 2) Department of Materials Structure Science, School of High Energy Accelerator Science, The Graduate University for \\ Advanced Studies (SOKENDAI), Tsukuba, Ibaraki, 305-0801 Japan. \\ 3) Structure Analysis Department, Materials Characterization Division, Futtsu Unit, Nippon Steel Technology Co., Ltd., 20-1 \\ Shintomi, Futtsu, Chiba, 293-0011 Japan. \\ 4) Photon Factory, Institute of Materials Structure Science, High Energy Accelerator Research Organization (KEK), Tsukuba, \\ Ibaraki, 305-0801 Japan.
}

(Received on March 31, 2020; accepted on August 3, 2020; J-STAGE Advance published date: September $11,2020)$

\begin{abstract}
The mass fraction of each crystalline phase in inorganic materials can be investigated using the Rietveld refinement of the X-ray diffraction (XRD) patterns. For quantitative analysis, differences in the values of the linear absorption coefficient, $\mu$, among the crystalline phases must be considered when certain $X$-ray sources are used, because such differences often affect their mass fractions. Herein, we evaluate the effects of the differences between the $\mathrm{Cu}$ and $\mathrm{Co} K \alpha \mathrm{X}$-rays on the mass fractions of the crystalline phases in iron sintered ores using the XRD-Rietveld method by performing two types of XRD measurements. Type 1 samples modeled materials with two different particle size combinations of $\alpha-\mathrm{Fe}_{2} \mathrm{O}_{3}$ and $\mathrm{ZnO}$. Type 2 samples used powder mixtures to simulate iron sintered ores composed of $\alpha-\mathrm{Fe}_{2} \mathrm{O}_{3}$, and synthesized SFCA and SFCA-I in various mass fractions. Moreover, a correction method was developed using the TaylorMatulis (TM) correction that considers the $\mu$ of each phase and the average particle diameter $R$ of each crystalline phase determined by scanning electron microscopy with energy dispersive spectroscopy. For type 1 samples, results that were in good agreement with the initially-charged mass fractions could be obtained using the TM correction, even in the presence of significant differences in $R$ between $\alpha-\mathrm{Fe}_{2} \mathrm{O}_{3}$ and $\mathrm{ZnO}$. The results for type 2 samples confirmed that quantitatively accurate mass fractions could be obtained using the TM correction with an accuracy of approximately \pm 3 mass $\%$ for $\mathrm{Cu}$ and Co sources, whereas the error was greater than \pm 3 mass $\%$ for $\mathrm{Cu}$ source when the TM correction was not applied.
\end{abstract}

KEY WORDS: sintered ore; calcium ferrite; XRD; the Rietveld method; micro-absorption effect.

\section{Introduction}

In the Asia-Pacific region, approximately 80 mass $\%$ of the iron processed in a blast furnace is obtained from iron sintered ores that consists primarily of $\alpha-\mathrm{Fe}_{2} \mathrm{O}_{3}, \mathrm{Fe}_{3} \mathrm{O}_{4}$, and silico-ferrites of calcium and aluminum $\left(\mathrm{SFCA}, \mathrm{Ca}_{2}(\mathrm{Ca}\right.$, $\mathrm{Fe}, \mathrm{Al})_{6}(\mathrm{Fe}, \mathrm{Al}, \mathrm{Si})_{6} \mathrm{O}_{20},{ }^{1)}$ and SFCA-I $\left((\mathrm{Ca}, \mathrm{Fe})_{4}(\mathrm{Fe}\right.$, $\left.\left.\mathrm{Al})_{16} \mathrm{O}_{28}\right)^{2)}\right)$. In addition, iron sintered ores contain less than 10 mass $\%$ of silicate slag and amorphous materials. The crystalline type and amount of each phase are considered to be important factors for controlling the characteristics of

* Corresponding author: E-mail: harano.ya6.takayuki@jp.nipponsteel.com iron sintered ores such as strength and reducibility. ${ }^{3,4)}$ To quantify the crystalline phases, generally the area ratios of microtextures in cross-sectional optical microscopy images have been used. ${ }^{5}$ ) Other studies have been conducted to evaluate the mass fractions of the crystalline phases in iron sintered ores using electron probe microanalysis or scanning electron microscopy with energy dispersive spectroscopy (SEM-EDS) ${ }^{6,7)}$ However, the identification of SFCA and SFCA-I by optical microscopy is challenging because both the chemical compositions and densities of these phases are quite similar. In addition, the solution ranges for their chemical compositions have not been determined, particularly for the non-equilibrium processes. 
The X-ray diffraction (XRD) Rietveld method $^{8)}$ has been widely used for the quantitative analysis of crystal structures and their mass fractions in crystalline materials. ${ }^{9)}$ The Rietveld method reproduces the experimental diffraction pattern for powder mixtures by simulation based on the crystallographic parameters of each phase such as the unit-cell type, atomic species, and atomic coordinates. These are used to mathematically determine the diffraction peak intensities and shapes. It is also possible to optimize the lattice parameters, the atomic occupancy of each site, and the mass fractions of the crystal phases in the samples using the non-linear least squares fitting method. ${ }^{8,9)}$ In the Rietveld refinement of XRD patterns, in some cases, it is noted that each crystalline phase cannot be accurately quantified because of the particular combination of the samples and X-ray sources. Free software (RIETAN-FP, ${ }^{10)}$ Profex, ${ }^{11)}$ MAUD $^{12)}$ ) as well as commercial software (PDXL2, HighScore ${ }^{\circledR},{ }^{13)}$ Siroquant ${ }^{14)}$ ) packages have been widely used to analyze X-ray and neutron diffraction patterns.

The XRD-Rietveld method has been applied to iron sintered ores. ${ }^{15,16)}$ However, in this case, particular attention must be paid to the following factors: (a) Fe, which is the main component of the ores and iron sintered ores, absorbs $\mathrm{Cu} \mathrm{K \alpha} \mathrm{X}$-rays that are often used as a X-ray source for XRD. (b) Iron sintered ores are composed of crystalline phases with a wide range of particle diameter sizes. Therefore, micro-absorption (MA) effects ${ }^{17)}$ must be considered in the determination of the mass fractions of the different crystalline-phase components using the XRD-Rietveld method.

Generally, under X-ray irradiation, a portion of the X-rays are absorbed by the sample. ${ }^{18)}$ The linear absorption coefficient $\mu$ that represents the degree of absorption depends on the product of the mass absorption coefficient $\mu_{\mathrm{m}}$ and density $\rho$. These are determined by the atomic composition of each crystalline phase and the wavelengths (photon energy) of the incident X-rays. Furthermore, in the case of multi-phase powder samples, the XRD peak intensities of each crystalline phase varies depending on the particle diameter and packing fraction in the sample. This effect is known as the MA effect and can give rise to mass fraction errors. Brindley's correction ${ }^{19)}$ and a more advanced method (Taylor-Matulis (TM) correction ${ }^{20)}$ ) were previously proposed to correct the MA effect, and are expected to reduce the mass fraction error and improve the accuracy of the mass fractions of the crystalline phases in inorganic materials. Iron sintered ores consist of multiple crystalline phases that have similar crystal structures, a complicated solution with a range of cation sites, and some low-crystallinity phases. These may also affect the quantitative accuracy of the Rietveld refinement and the effect of the TM correction. A detailed discussion and quantitative analysis of the MA effects have been reported previously. ${ }^{21-24)}$

However, few studies have been conducted on the evaluation of the MA affect for the anticipated application of Rietveld analysis to iron sintered ores and iron ores. B. M. Pederson et al. evaluated the usefulness of the Brindley correction using commercial reagents. ${ }^{25}$ ) However, it is difficult to treat the linear absorption coefficient and the particle diameter of each crystal phase individually for the raw materials of steel, which may consist of phases with various degrees of milling as well as amorphous phases produced during the preparation of the samples for diffraction measurements. Therefore, a unified correction factor of the MA effect should not be applied to all crystalline phases in the sample. In addition, for iron sintered ores, there is an additional problem that this material tends to produce a large MA effect. This is because the constituent phases of the ores have relatively larger X-ray absorption contrast and varied particle sizes due to the hardness differences among the phases. Therefore, the degree of the MA effect and the utility of the TM correction ${ }^{20)}$ are important motivations for the evaluation of the raw materials in iron-making process.

In laboratory investigations, $\mathrm{Cu} K \alpha$ or $\mathrm{Co} K \alpha$ radiation sources with the $K \alpha_{1}$ energies of 8.048 and $6.924 \mathrm{keV}$, respectively, have been generally used as X-ray sources for powder XRD. For XRD using $\mathrm{Cu} K \alpha$ radiation, the absorption coefficient of Fe is very large immediately above the Fe $K$ absorption edge $(7.120 \mathrm{keV})$ so that the diffraction patterns of the phases with high Fe content do not reflect real mass fractions. For an accurate quantification of the individual phases in a sample, a combination of the X-ray source and crystalline phase in the sample should be considered. Traditionally, $\mathrm{Cu}$ X-ray sources have been widely used in the metal industries because of their long lifetime, low cost, and high X-ray power. Therefore, in some cases, $\mathrm{XRD}$ measurements must be conducted using $\mathrm{Cu} K \alpha$ radiation even though iron sintered ores contain large amounts of Fe. In other words, it is also assumed that a specific X-ray source must be used due to equipment constraints.

In this study, to improve the accuracy of the mass fractions of the individual crystal phases in iron sintered ores by the XRD-Rietveld method, the correction effect was verified for two types of samples. The first type of samples (type 1) is the mixture samples of $\alpha-\mathrm{Fe}_{2} \mathrm{O}_{3}$ and $\mathrm{ZnO}$ with different particle sizes. In each sample, the mass fraction of each crystalline phase was calculated by the Rietveld refinement to evaluate the usefulness of the TM correction for samples with different particle sizes. The other types of sample (type 2) are mixtures of simulated iron sintered ores that consist of $\alpha-\mathrm{Fe}_{2} \mathrm{O}_{3}, \mathrm{SFCA}$, and SFCA-I. To evaluate the influence of the X-ray radiation sources not only $\mathrm{Cu} K \alpha$ (expected large MA effect) but also Co $K \alpha$ (expected small MA effect), as general X-ray sources for XRD in laboratory studies, XRD measurements were performed to determine the quantitative values of the individual crystal phases in the samples.

\section{Experimental Methods}

\subsection{Sample Preparation}

To verify that the mass fraction accuracy of the XRDRietveld method can be improved by the TM corrections even when the MA effects are large, (1) sample mixtures of $\alpha-\mathrm{Fe}_{2} \mathrm{O}_{3}$ and $\mathrm{ZnO}$ with different particle diameters and (2) sample mixtures composed of phases with different iron contents $\left(\alpha-\mathrm{Fe}_{2} \mathrm{O}_{3}\right.$, SFCA, SFCA-I) were prepared.

Sample mixtures of $\alpha-\mathrm{Fe}_{2} \mathrm{O}_{3}$ and $\mathrm{ZnO}$ with different particle diameters (type 1 samples) were used for the evaluation of the MA effect and the effect of the correction for a typical sample that consists of a phase $\left(\alpha-\mathrm{Fe}_{2} \mathrm{O}_{3}\right)$ with a large particle diameter and linear absorption coefficient and another phase $(\mathrm{ZnO})$ with small particle diameter and linear absorption coefficient. Powder samples in which $\alpha-\mathrm{Fe}_{2} \mathrm{O}_{3}$ 
and $\mathrm{ZnO}$, with the average particle diameters of 0.5 or 20 $\mu \mathrm{m}$ and $0.6 \mu \mathrm{m}$, respectively, were mixed in an equal mass fraction $(50 \% / 50 \%)$. Samples with the same mass fraction mixtures of $\alpha-\mathrm{Fe}_{2} \mathrm{O}_{3}$ and $\mathrm{ZnO}$ were prepared by mixing reagent grade $\alpha-\mathrm{Fe}_{2} \mathrm{O}_{3}$ (Kojundo Chemical Laboratory Co., Ltd., Japan, $4 \mathrm{~N}, 0.5 \mu \mathrm{m})$ or $\alpha-\mathrm{Fe}_{2} \mathrm{O}_{3}$ with a $20-\mu \mathrm{m}$ average particle size (measured by Laser scattering measurement) obtained by grinding 2-mm particles of $\alpha-\mathrm{Fe}_{2} \mathrm{O}_{3}$ (Kojundo Chemical Laboratory Co., Ltd., Japan, 4N), and $\mathrm{ZnO}$ (Kojundo Chemical Laboratory Co., Ltd., Japan, 4N, 0.6 $\mu \mathrm{m})$ in equal mass $(50 \% / 50 \%)$.

Sample mixtures composed of phases with different iron contents $\left(\alpha-\mathrm{Fe}_{2} \mathrm{O}_{3}, \mathrm{SFCA}, \mathrm{SFCA}-\mathrm{I}\right)$ (type 2 samples) were used to evaluate the accuracy of the mass fraction of each phase in the simulated iron sintered ores for the correction. Six model samples consisting of three compounds were prepared. Specifically, $\alpha-\mathrm{Fe}_{2} \mathrm{O}_{3}$, which is the main phase in iron sintered ores, and two types of synthesized silico-ferrites of calcium and aluminum (SFCA, SFCA-I), that have particularly unique chemical compositions, ${ }^{1,2}$ were mixed in various mass fractions. Samples of SFCA and SFCA-I were synthesized by conventional powder sintering following the procedures reported by J. D. I. Hamilton et al. ${ }^{1)}$ and W. G. Mumme et al. ${ }^{2)}$ Their detailed crystal structures including atomic coordinates were reported in the literatures. ${ }^{1,2)}$ For the synthesis of single-phase SFCA and SFCA-I, reagent grade $\alpha-\mathrm{Fe}_{2} \mathrm{O}_{3}$ (Kojundo Chemical Laboratory Co., Ltd., Japan, 4N, $0.5 \mu \mathrm{m}$ ), $\mathrm{CaCO}_{3}$ (Kanto Chemical Co., Ltd., Japan, $4 \mathrm{~N}, 12 \mu \mathrm{m}$ ), $\alpha-\mathrm{SiO}_{2}$ (Kojundo Chemical Laboratory Co., Ltd., Japan, 99\%, $1 \mu \mathrm{m}$ ), $\alpha-\mathrm{Al}_{2} \mathrm{O}_{3}$ (Kojundo Chemical Laboratory Co., Ltd., Japan, 4N, $1 \mu \mathrm{m}$ ), and MgO (Kojundo Chemical Laboratory Co., Ltd., Japan 4N, $0.6 \mu \mathrm{m}$ ) were used. Powder mixtures (approximately $3 \mathrm{~g}$ ) prepared with the composition shown in Table 1 were pelletized into two or three tablets with a diameter of $13 \mathrm{~mm}$ at a pressure of $34.5 \mathrm{kN}$ and then were calcined at $800^{\circ} \mathrm{C}$. Annealing was performed at $1200^{\circ} \mathrm{C}$ (SFCA) and $1230^{\circ} \mathrm{C}$ (SFCA-I) for $60 \mathrm{~h}$, respectively. The tablets were then pulverized and pelletized into new tablets with the same size, and the same heat treatment was repeated three times. Figure 1 shows the XRD patterns $(\mathrm{Cu} K \alpha)$ of the synthesized SFCA and SFCAI. Although $\alpha-\mathrm{Fe}_{2} \mathrm{O}_{3}$ was included in the synthesized SFCA and SFCA-I samples, single phases with a purity of greater than $99 \%$ and $95 \%$ were obtained, respectively, as deduced from the XRD peak intensities of each sample. Synthesized SFCA, SFCA-I, and $\alpha-\mathrm{Fe}_{2} \mathrm{O}_{3}$ were mixed at the mass fractions listed in Table 2 to prepare model samples. $\alpha-\mathrm{Fe}_{2} \mathrm{O}_{3}$ was prepared by pulverizing a reagent grade shot (Kojundo Chemical Laboratory Co., Ltd., Japan 4N) with an average particle size of approximately $2 \mathrm{~mm}$. After blending, each model sample was pulverized and mixed for approximately 30 min using an agate mortar and a pestle to ensure homogeneity.

Table 1. Initial compositions of SFCA and SFCA-I (mass $\%$ ).

\begin{tabular}{cccccc}
\hline & $\mathrm{CaCO}_{3}$ & $\alpha-\mathrm{Fe}_{2} \mathrm{O}_{3}$ & $\alpha-\mathrm{Al}_{2} \mathrm{O}_{3}$ & $\alpha-\mathrm{SiO}_{2}$ & $\mathrm{MgO}$ \\
\hline $\mathrm{SFCA}^{1)}$ & 25.7 & 59.1 & 5.3 & 7.8 & 2.1 \\
$\mathrm{SFCA-I}^{2)}$ & 18.2 & 76.9 & 4.9 & - & - \\
\hline
\end{tabular}

\subsection{XRD Measurements}

To verify that the accuracy of the XRD-Rietveld method can be improved by the TM corrections even when the MA effects are large, two cases are considered; (1) mixture samples of $\alpha-\mathrm{Fe}_{2} \mathrm{O}_{3}$ and $\mathrm{ZnO}$ with different particle sizes using X-ray sources of $\mathrm{Cu} K \alpha$ and (2) samples simulated iron sintered ores using X-ray sources of $\mathrm{Cu}$ and $\mathrm{Co} K \alpha$.

$\mathrm{X}$-rays of $\mathrm{Cu} K \alpha$ radiation were used for the XRD measurements performed to verify the mass fraction accuracy of the TM correction, while in the XRD measurements performed to examine the effect of X-ray sources, the XRD patterns were obtained using X-rays of both $\mathrm{Cu} K \alpha$ and Co $K \alpha$ sources. XRD patterns were analyzed by the Rietveld method to investigate the mass fractions of the crystalline phases. In addition, we attempted to correct each quantitative mass fraction using the correction of J. C. Taylor et $a .^{20)}$ in which we considered the linear absorption coefficient and average particle diameter of each phase. In type 2 samples, the average particle diameters of $\alpha-\mathrm{Fe}_{2} \mathrm{O}_{3}, \mathrm{SFCA}$, SFCA-I in each sample powder obtained by SEM-EDS with automatic particle analysis were also used for the correction.

A Smartlab diffractometer (Rigaku, Japan) was used for XRD measurements. Powders of model samples were filled in a sample holder (sample part: $\phi 20 \mathrm{~mm} \times 0.2 \mathrm{~mm}$ depth), and XRD measurements were performed. For $\mathrm{Cu} K \alpha$ radiation, the tube current and tube voltage were set at $40 \mathrm{~mA}$ and $40 \mathrm{kV}$, respectively. For Co $K \alpha$ radiation, the tube current and tube voltage were set at $36 \mathrm{~mA}$ and $40 \mathrm{kV}$, respectively. The goniometer radius was $285 \mathrm{~mm}$. A high-speed, one-dimensional detector D/teX (Rigaku, Japan) was used as the X-ray detector, and measurements were performed using the Bragg-Brentano focusing geometry (i.e., the $K \beta$

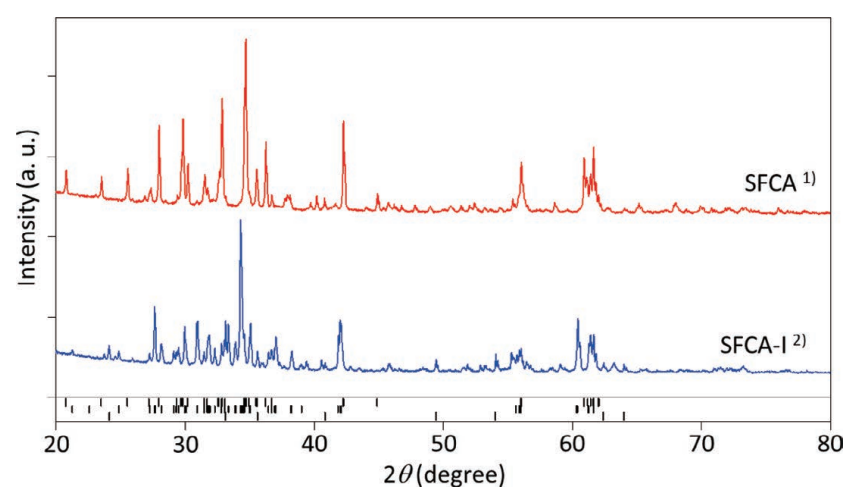

Fig. 1. XRD patterns $(\mathrm{Cu} K \alpha)$ of synthesized SFCA (red) and SFCA-I (blue). The rows of the bars indicate the positions of the XRD peaks of SFCA, SFCA-I, and $\alpha-\mathrm{Fe}_{2} \mathrm{O}_{3}$ reported in previous studies ${ }^{1,2,26)}$ from the top.

Table 2. Mass fractions of model samples (mass $\%$ ).

\begin{tabular}{cccc}
\hline No. & $\alpha-\mathrm{Fe}_{2} \mathrm{O}_{3}$ & SFCA & SFCA-I \\
\hline 1 & 50.0 & 25.0 & 25.0 \\
2 & 49.8 & 12.6 & 37.6 \\
3 & 49.8 & 37.5 & 12.7 \\
4 & 50.0 & 33.4 & 16.6 \\
5 & 50.0 & 39.8 & 10.3 \\
6 & 49.9 & 45.1 & 5.0 \\
\hline
\end{tabular}


filter method, with $\mathrm{Cu} K \alpha$ and $\mathrm{Co} K \alpha$ using $\mathrm{Ni}$ and $\mathrm{Fe}$ filters, respectively). The measurement conditions were as follows: Measurement angle range $2 \theta=20-80^{\circ}$, step angle width $\Delta 2 \theta=0.02^{\circ}$, scan speed $=1 \% \mathrm{~min}$, and sample azimuth rotation speed $=60 \mathrm{rpm}$. The divergence slit (DS) was $1 / 2^{\circ}$, and the widths of the receiving slits RS1 and RS2 were 8 and $13 \mathrm{~mm}$, respectively.

To carry out the XRD-Rietveld analysis, the PDXL2 software (version 2.8.1.1, Rigaku, Japan) was used. The initial crystallographic parameters of each crystalline phase used in the analysis were as follows: ICDD card number 01-080$2377^{26)}$ for $\alpha-\mathrm{Fe}_{2} \mathrm{O}_{3}$, ICDD card number 01-079-0206 ${ }^{27)}$ for $\mathrm{ZnO}$, parameters reported by J. D. I. Hamilton ${ }^{1)}$ for SFCA, and parameters reported by W. G. Mumme ${ }^{2)}$ for SFCA-I. In the analysis, the atomic coordinates and temperature factors were fixed at the initial values. The full width at half maximum parameters $(U, V, W)$ of the profile function for the samples of both types 1 and 2 of $\alpha-\mathrm{Fe}_{2} \mathrm{O}_{3}$ and those of the other crystal phases were set to the same values, and non-linear least square fitting was performed. The Rietveld method is described in detail in the literature. ${ }^{10)}$

\subsection{Taylor-Matulis Correction}

According to J. C. Taylor et al. ${ }^{20)}$ the correction factor $\tau_{i}$ for the MA effect in XRD patterns for the quantitative value of the $i$ th crystal phase can be expressed by Eq. (1):

$$
\tau_{i}=\frac{1}{A_{i}} \int_{0}^{A_{i}} e^{-\left(\mu_{i}-\bar{\mu}\right) x} d A_{i}
$$

where $A_{i}$ is the particle volume, $\mu_{i}$ is the linear absorption coefficient of the $i$ th crystal phase, and $\bar{\mu}$ is the average linear absorption coefficient of the samples. $\bar{\mu}$ is calculated from the mass fraction obtained prior to the TM correction. Assuming that the particle is a perfect sphere, Eq. (1) can be simplified, yielding the correction coefficient $\tau_{i}$ given by Eq. (2):

$$
\tau_{i}=\frac{3}{X^{3}}\left(e^{X}\left(X^{2}-2 X+2\right)-2\right)
$$

where $X=\left(\mu_{i}-\bar{\mu}\right) R_{i}$. and $R_{i}$ is the average diameter of the $i$ th crystalline phase. When the correction coefficient $\tau_{i}$ is calculated in this manner, the mass fraction of the $i$ th crystalline phase is expressed as shown in Eq. (3),

$$
w_{i}=\frac{s_{i} Z_{i} M_{i} V_{i} / \tau_{i}}{\sum_{j=1}^{n} s_{j} Z_{j} M_{j} V_{j} / \tau_{j}}=\frac{w_{i}^{\prime} / \tau_{i}}{\sum_{j=1}^{n} w_{j}^{\prime} / \tau_{j}} .
$$

where $s_{i}, Z_{i}, M_{i}, V_{i}, w_{i}$, and $w_{i}^{\prime}$ are the scale factor in the XRD-Rietveld method, the number of molecules per unit cell, the formula weight, unit cell volume, and the mass fraction after and before correction of the $i$ th crystal phase, respectively. Here, $n$ is the number of the crystal phases in the samples.

\subsection{SEM-EDS Measurements}

SEM-EDS measurements were performed to determine the average particle diameter of $\alpha-\mathrm{Fe}_{2} \mathrm{O}_{3}$ and the multicomponent calcium ferrite included in sample No. 1 with the mass fractions shown in Table 2. Metal Quality Analyzer (MQA, Thermo Fisher Scientific, USA) was used for the

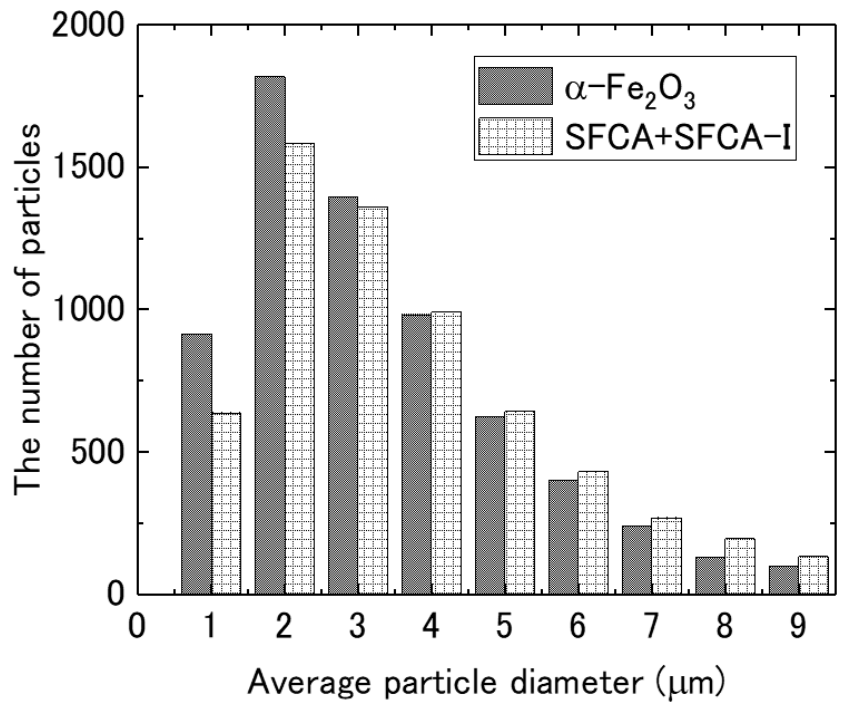

Fig. 2. Distributions of the average particle diameter sizes of $\alpha-\mathrm{Fe}_{2} \mathrm{O}_{3}$ and multi-component calcium ferrite (SFCA+ SFCA-I) obtained by SEM-EDS measurements.

SEM-EDS measurements. The sample was prepared as follows. An aqueous solution in which the powder sample No. 1 was prepared (as described in Section 2.1) was dispersed and collected with a dropper. Dispersion was achieved by dropping the sample particles on a $10 \times 10 \times \mathrm{t} 1 \mathrm{~mm}^{3} \mathrm{Si}$ substrate with a carbon tape attached. After drying, the particle diameters and compositions of approximately 7000 particles were analyzed at approximately 3000 particles/h using an automatic particle analysis function of MQA. In this study, the particles in which only $\mathrm{Fe}$ and $\mathrm{O}$ was detected by EDS were identified as $\alpha-\mathrm{Fe}_{2} \mathrm{O}_{3}$, and the particles in which $\mathrm{Al}, \mathrm{Ca}, \mathrm{Fe}, \mathrm{O}$, and $\mathrm{Si}$ were detected were identified as multi-component calcium ferrite (SFCA + SFCA-I) because SFCA and SFCA-I that are found in different solid solution states cannot be distinguished in iron sintered ores in real steel works. In addition, each particle size distribution was measured simultaneously. Figure 2 shows the distributions of the particle diameters of $\alpha-\mathrm{Fe}_{2} \mathrm{O}_{3}$ and calcium ferrite (SFCA + SFCA-I). The average particle diameters of $\alpha-\mathrm{Fe}_{2} \mathrm{O}_{3}$ and calcium ferrite were defined as the arithmetic mean of the particles measured in the two cardinal and two ordinal directions.

\section{Results and Discussion}

To verify that the accuracy of the XRD-Rietveld method can be improved by the TM corrections even when MA effects are large, two cases are considered; (1) sample mixtures of $\alpha-\mathrm{Fe}_{2} \mathrm{O}_{3}$ and $\mathrm{ZnO}$ particles with different diameters using X-ray sources of $\mathrm{Cu} K \alpha$ and (2) samples simulated iron sintered ores using X-ray sources of $\mathrm{Cu}$ and $\mathrm{Co} K \alpha$.

\subsection{Validation of the Taylor-Matulis Correction for the Micro-absorption Effects}

Figure 3 shows the XRD patterns of $\alpha-\mathrm{Fe}_{2} \mathrm{O}_{3}$ and $\mathrm{ZnO}$ in the $1: 1$ mass ratio obtained using a $\mathrm{Cu} K \alpha \mathrm{X}$-ray source. The blue line shows the pattern of the mixture of $\alpha-\mathrm{Fe}_{2} \mathrm{O}_{3}$ and $\mathrm{ZnO}$ with the average particle sizes of 0.5 and $0.6 \mu \mathrm{m}$, respectively. The red line shows the pattern of the mixture 


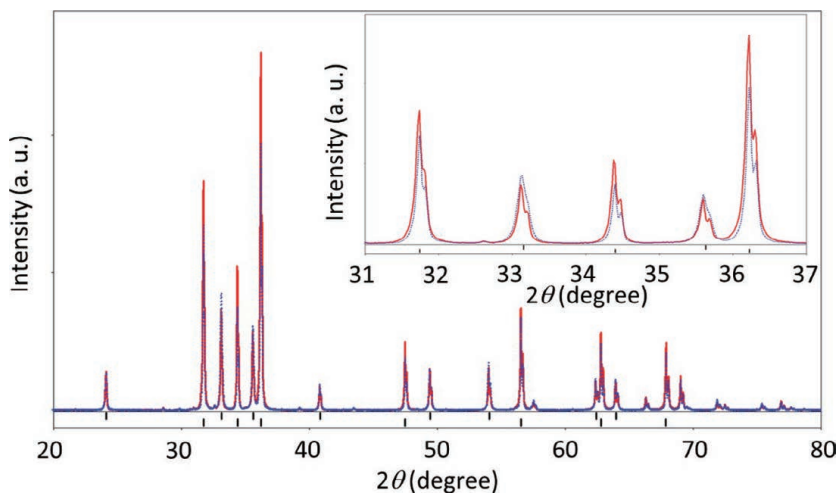

Fig. 3. XRD patterns of $\alpha-\mathrm{Fe}_{2} \mathrm{O}_{3}$ and $\mathrm{ZnO}$ in the $1: 1$ mass ratio measured using $\mathrm{Cu} K \alpha$ radiation. Dotted blue and red lines show the diffraction patterns for the samples where the average particle sizes of $\alpha-\mathrm{Fe}_{2} \mathrm{O}_{3}$ and $\mathrm{ZnO}$ are 0.5 and $0.6 \mu \mathrm{m}$, and 20 and $0.6 \mu \mathrm{m}$, respectively. The inset shows the region where the difference is prominent. The $R_{\mathrm{wp}} / S$ factors of the Rietveld analysis are $3.42 \% / 2.52$ and $2.56 \% / 1.91$, respectively. The rows of the bars indicate the positions of the XRD peaks of $\alpha-\mathrm{Fe}_{2} \mathrm{O}_{3}$ and $\mathrm{ZnO}$ reported in previous studies ${ }^{26,27)}$ from the top.

of $\alpha-\mathrm{Fe}_{2} \mathrm{O}_{3}$ and $\mathrm{ZnO}$ with average particle sizes of 20 and $0.6 \mu \mathrm{m}$, respectively. For the powder sample with the average particle diameters of $20 \mu \mathrm{m}$ for $\alpha-\mathrm{Fe}_{2} \mathrm{O}_{3}$ and $0.6 \mu \mathrm{m}$ for $\mathrm{ZnO}$, the quantitative values $\left(\alpha-\mathrm{Fe}_{2} \mathrm{O}_{3}: 35\right.$ mass $\%$, $\mathrm{ZnO}$ : 65 mass \%) deviated significantly from the initially-charged mass fraction. In the Rietveld refinement, the corresponding $R_{\text {wp }} / S$ factors were $3.42 \% / 2.52$ and $2.56 \% / 1.91$, respectively. Note that $R_{\mathrm{wp}}$ and $S$ are the weighted profile $R$-factor and the goodness-of-fit, respectively. The correction coefficient $\tau$ was calculated by the TM correction using the linear

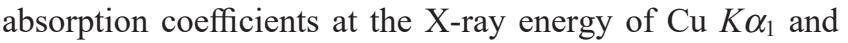
the average particle diameters of $\alpha-\mathrm{Fe}_{2} \mathrm{O}_{3}$ and $\mathrm{ZnO}$. The linear absorption coefficients and particle diameters of $\alpha-\mathrm{Fe}_{2} \mathrm{O}_{3}$ and $\mathrm{ZnO}$, as well as $\tau_{\mathrm{Fe} 2 \mathrm{O} 3}$ and $\tau_{\mathrm{znO}}$ are presented in Table 3 . It should be noted that $\tau_{\mathrm{Fe} 2 \mathrm{O} 3}$ and $\tau_{\mathrm{znO}}$ were calculated using the initially-charged mass fraction of each sample, because the goal of the experiments on type 1 samples was to examine the accuracy and usefulness of the TM correction.

The quantitative mass fractions before and after the application of the TM correction of the XRD pattern for the samples with the average particle sizes of $\alpha-\mathrm{Fe}_{2} \mathrm{O}_{3}$ and $\mathrm{ZnO}$ of 0.5 and $0.6 \mu \mathrm{m}$, respectively, are depicted in Fig. 4 as A and A', respectively. Both sets of mass fractions results were almost identical to each other because the measurement conditions were ideal in terms of the average particle diameters of $\alpha-\mathrm{Fe}_{2} \mathrm{O}_{3}$ and $\mathrm{ZnO}$. For the XRD patterns of the samples with the average particle diameters of $\alpha-\mathrm{Fe}_{2} \mathrm{O}_{3}$ and $\mathrm{ZnO}$ of 20 and $0.6 \mu \mathrm{m}$, the quantitative mass fractions before and after the application of the TM correction are depicted as B and B' in Fig. 4, respectively. Although the B results could not reproduce the mixing mass fractions, it was confirmed through the calculated correction factors $\tau_{\mathrm{Fe} 2 \mathrm{O} 3}$ and $\tau_{\mathrm{znO}}$ that the quantitative values of B' as shown in Fig. 4 were nearly the same as the initially-charged composition, even when the particle diameter difference was large. The penetration depth $t_{\mathrm{p}}$ is given as $\mu t_{\mathrm{p}}=1$, and $t_{\mathrm{p}}=18$ and $70 \mu \mathrm{m}$ for $\alpha-\mathrm{Fe}_{2} \mathrm{O}_{3}$ and $\mathrm{ZnO}$, respectively when $\mathrm{Cu} K \alpha$ is used. On the other hand, $t_{\mathrm{p}}=89$ and $46 \mu \mathrm{m}$ for $\alpha-\mathrm{Fe}_{2} \mathrm{O}_{3}$ and $\mathrm{ZnO}$, respectively when $\mathrm{Co} K \alpha$ is used. Therefore, these
Table 3. MA correction parameters for $\alpha-\mathrm{Fe}_{2} \mathrm{O}_{3}$ and $\mathrm{ZnO}$ mixture specimens.

\begin{tabular}{ccccc}
\hline Species & $\begin{array}{c}\text { Linear absorption } \\
\text { coefficient } \mu_{i}\left(\mathrm{~cm}^{-1}\right)\end{array}$ & $\begin{array}{c}\text { Averaged particle } \\
\text { diameter } R(\mu \mathrm{m})\end{array}$ & $\begin{array}{c}\bar{\mu} \\
\left(\mathrm{cm}^{-1}\right)\end{array}$ & $\begin{array}{c}\text { Correction } \\
\text { factor } \tau\end{array}$ \\
\hline$\alpha-\mathrm{Fe}_{2} \mathrm{O}_{3}$ & 1119 & 0.5 & 689.5 & 0.984 \\
& 1119 & 20 & 689.5 & 0.533 \\
$\mathrm{ZnO}$ & 260 & 0.6 & 689.5 & 1.02 \\
\hline
\end{tabular}

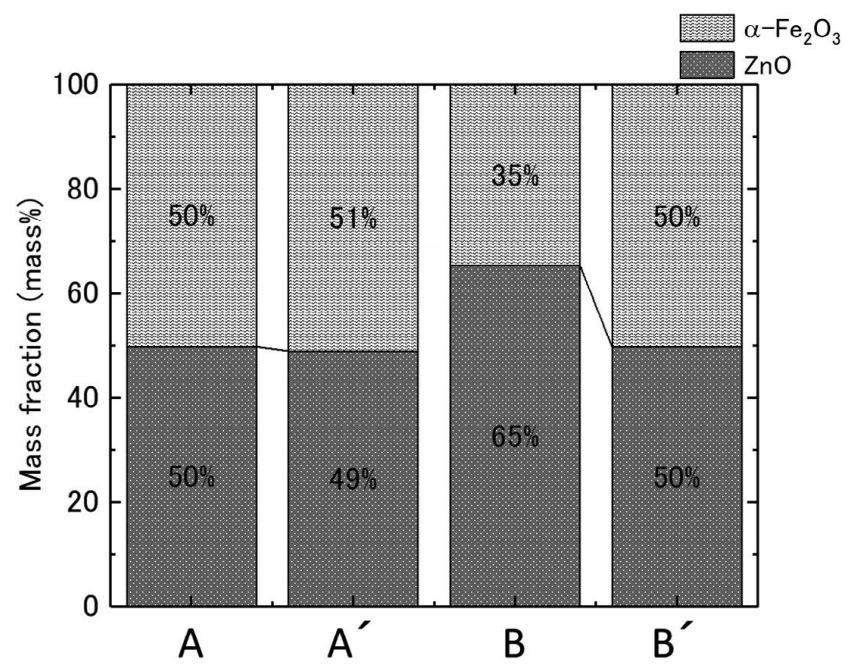

Fig. 4. Mass fractions before and after the Taylor-Matulis correction determined by the Rietveld analysis of each XRD pattern shown in Fig. 3. A and A' indicate the quantitative values before and after the Taylor-Matulis correction of the XRD patterns with the average $\alpha-\mathrm{Fe}_{2} \mathrm{O}_{3}$ and $\mathrm{ZnO}$ particle sizes of 0.5 and $0.6 \mu \mathrm{m}$, respectively. B and B' indicate the quantitative values before and after the correction of the XRD patterns for $\alpha-\mathrm{Fe}_{2} \mathrm{O}_{3}$ and $\mathrm{ZnO}$ with the average particle diameter sizes of 20 and $0.6 \mu \mathrm{m}$, respectively.

results show that it is particularly important to consider the MA effects when the particle diameter of the phase that absorbs the X-ray is as large as the penetration depth $t_{\mathrm{p}}$.

It was confirmed that the accuracy of the XRD-Rietveld method can be improved by the TM correction through the comparison of the results for the mixture samples of $\alpha$ - $\mathrm{Fe}_{2} \mathrm{O}_{3}$ and $\mathrm{ZnO}$ with different particle diameters, namely (A) 0.5 and $0.6 \mu \mathrm{m}$, and (B) 20 and $0.6 \mu \mathrm{m}$, respectively.

\subsection{The Taylor-Matulis Correction of the Difference in the X-ray Sources in Samples Simulated Iron Sin- tered Ores}

We next considered the case of type 2 samples. Table 4 shows the average particle diameters as described in Section 2.4, the linear absorption coefficients of $\mathrm{Cu} K \alpha_{1}$ and Co $K \alpha_{1}$, and the $\tau$ factors of $\alpha-\mathrm{Fe}_{2} \mathrm{O}_{3}$, SFCA, and SFCA-I for each model sample. The average particle diameters of $\alpha-\mathrm{Fe}_{2} \mathrm{O}_{3}$ and multi-component calcium ferrite were 4.1 and $4.6 \mu \mathrm{m}$, respectively, showing that a correction of $5-8 \%$ is required for $\mathrm{Cu} K \alpha$. The grain sizes are smaller than the values of the penetration depth $t_{\mathrm{p}}$, and the MA effects are not as strong as in type 1 samples.

In the following analysis, the TM correction calculations were performed for all samples using the average particle diameters of $\alpha-\mathrm{Fe}_{2} \mathrm{O}_{3}$, SFCA, and SFCA-I in sample No. 
Table 4. Correction factors, $\tau$, for $\alpha-\mathrm{Fe}_{2} \mathrm{O}_{3}$ and silico-ferrite of calcium and aluminum (SFCA+SFCA-I).

\begin{tabular}{|c|c|c|c|c|c|c|c|}
\hline species & $\begin{array}{c}\mu \\
\left(\mathrm{Cu} K \alpha_{1}\right) \\
\left(\mathrm{cm}^{-1}\right)\end{array}$ & $\begin{array}{c}\mu \\
\left(\mathrm{Co} K \alpha_{1}\right) \\
\left(\mathrm{cm}^{-1}\right)\end{array}$ & $\begin{array}{c}\text { Averaged } \\
\text { particle } \\
\text { diameter } \\
R(\mu \mathrm{m})\end{array}$ & No. & $\begin{array}{c}\bar{\mu} \\
\left(\mathrm{cm}^{-1}\right)\end{array}$ & $\begin{array}{c}\text { Correction } \\
\text { factor } \\
\tau \text { for } \\
\mathrm{CuK} \alpha_{1}\end{array}$ & $\begin{array}{c}\text { Correction } \\
\text { factor } \\
\tau \text { for } \\
\text { Co } K \alpha_{1}\end{array}$ \\
\hline \multirow{6}{*}{$\alpha-\mathrm{Fe}_{2} \mathrm{O}_{3}$} & \multirow{6}{*}{1119} & \multirow{6}{*}{225} & \multirow{6}{*}{4.1} & 1 & 945.7 & 0.948 & 1.006 \\
\hline & & & & 2 & 961.2 & 0.953 & 1.007 \\
\hline & & & & 3 & 929.1 & 0.943 & 1.006 \\
\hline & & & & 4 & 934.9 & 0.945 & 1.006 \\
\hline & & & & 5 & 926.6 & 0.943 & 1.006 \\
\hline & & & & 6 & 919.6 & 0.941 & 1.006 \\
\hline \multirow{6}{*}{ SFCA } & \multirow{6}{*}{708} & \multirow{6}{*}{266} & \multirow{6}{*}{4.6} & 1 & 945.7 & 1.086 & 0.993 \\
\hline & & & & 2 & 961.2 & 1.092 & 0.993 \\
\hline & & & & 3 & 929.1 & 1.079 & 0.993 \\
\hline & & & & 4 & 934.9 & 1.082 & 0.993 \\
\hline & & & & 5 & 926.6 & 1.079 & 0.993 \\
\hline & & & & 6 & 919.6 & 1.076 & 0.993 \\
\hline \multirow{6}{*}{ SFCA-I } & \multirow{6}{*}{837} & \multirow{6}{*}{268} & \multirow{6}{*}{4.6} & 1 & 945.7 & 1.038 & 0.992 \\
\hline & & & & 2 & 961.2 & 1.044 & 0.993 \\
\hline & & & & 3 & 929.1 & 1.032 & 0.992 \\
\hline & & & & 4 & 934.9 & 1.034 & 0.992 \\
\hline & & & & 5 & 926.6 & 1.031 & 0.992 \\
\hline & & & & 6 & 919.6 & 1.029 & 0.992 \\
\hline
\end{tabular}

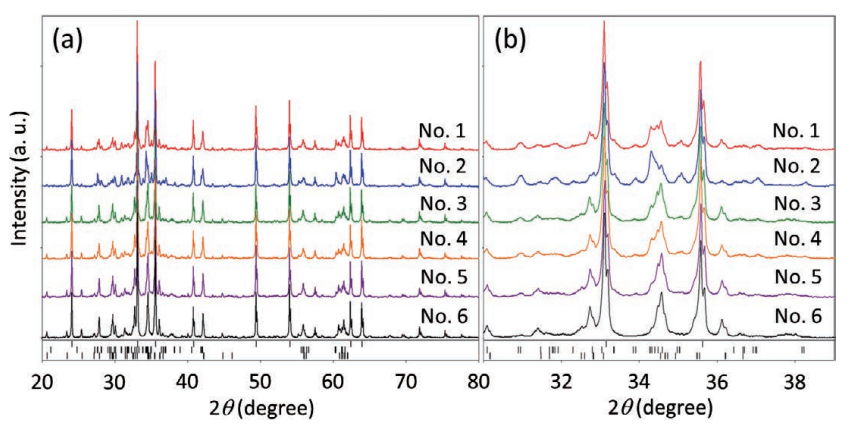

Fig. 5. (a) XRD patterns of the model samples (No. 1-6) consisting of $\alpha-\mathrm{Fe}_{2} \mathrm{O}_{3}$, SFCA, and SFCA-I using $\mathrm{Cu} K \alpha$. (b) Magnified view of a region of Fig. 5(a). The rows of the bars indicate the positions of XRD peaks of $\alpha-\mathrm{Fe}_{2} \mathrm{O}_{3}$, SFCA, and SFCA-I reported in previous studies ${ }^{1,2,26)}$ from the top.

1. The particle diameters of each crystalline phase in all samples can be considered to be approximately the same because all of the samples were prepared and mixed using the same method. The linear absorption coefficients of SFCA and SFCA-I were calculated using the compositions and density reported in the literature. ${ }^{1,2)}$

Figure 5 shows the XRD patterns of the model samples (Nos. 1-6) consisting of $\alpha-\mathrm{Fe}_{2} \mathrm{O}_{3}$, SFCA, and SFCA-I ${ }^{1,2,26}$ ) using $\mathrm{Cu} K \alpha$ radiation. In the bottom part of Fig. 5, the XRD patterns of $\alpha-\mathrm{Fe}_{2} \mathrm{O}_{3}$, SFCA, and SFCA-I reported in previous studies are shown. ${ }^{1,2,26)}$ The rows of the bars under patterns indicate the peak positions of $\alpha-\mathrm{Fe}_{2} \mathrm{O}_{3}$, SFCA, and SFCA-I from the top. Figure 6 shows an XRD pattern (red) of the model sample (No. 1) obtained using $\mathrm{Cu} K \alpha$, the simulated pattern (blue) obtained by the Rietveld method,

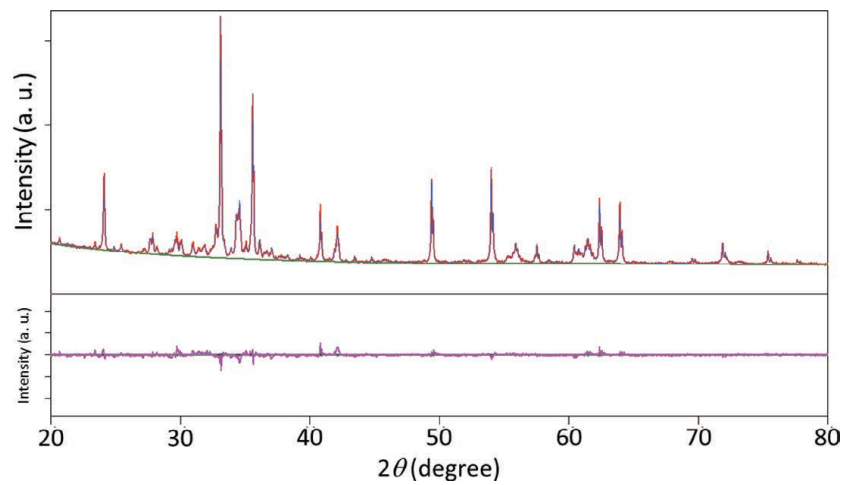

Fig. 6. XRD pattern (red) of the model sample (No. 1) obtained using $\mathrm{Cu} K \alpha$ radiation and the simulated pattern (blue) obtained by the Rietveld method, and the residual pattern (pink) showing the difference between the red and blue curves. The background pattern is shown by the green curve.

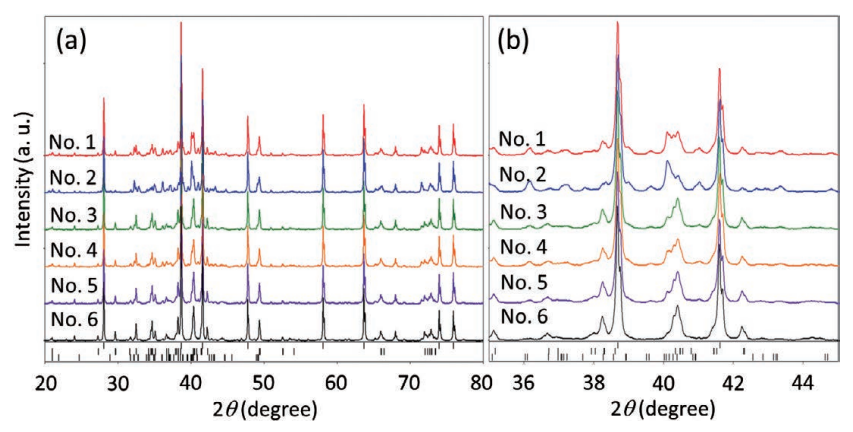

Fig. 7. XRD patterns of the model samples (No. 1-6). XRD patterns of the samples consisting of $\alpha-\mathrm{Fe}_{2} \mathrm{O}_{3}, \mathrm{SFCA}$, and SFCA-I obtained using Co $K \alpha$ radiation. The rows of bars under patterns indicate peak positions of $\alpha-\mathrm{Fe}_{2} \mathrm{O}_{3}, \mathrm{SFCA}$, and SFCA-I reported in previous studies ${ }^{1,2,26)}$ from the top.

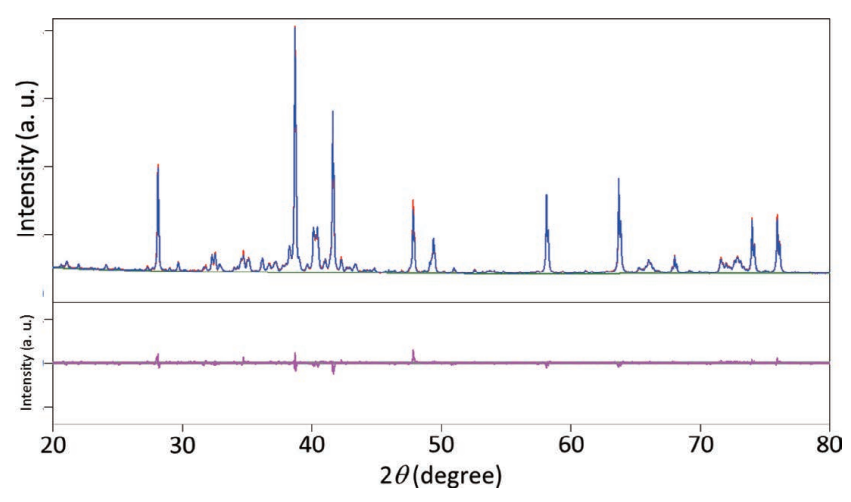

Fig. 8. XRD pattern (red) of the model sample (No. 1) obtained using Co $K \alpha$ radiation and the simulated pattern (blue) obtained by the Rietveld method, and residual pattern (pink) showing the difference between the red and blue curves. The background pattern is shown by the green curve.

and the residual pattern (pink) obtained as the difference between the red and blue curves. Figures 7 and 8 show the results corresponding to those presented in Figs. 5 and 6, respectively, but obtained using Co $K \alpha$ source. Figures 5 and 7 show that the intensity of the peaks near $2 \theta=34.5^{\circ}$ and $40.5^{\circ}$ changed due to the difference in the mass fraction between SFCA and SFCA-I, respectively. It was also confirmed that the measured XRD patterns presented in Figs. 6 and 8 could be reproduced well by the Rietveld refinement. 
Table 5 shows the $R_{\mathrm{wp}}$ and $S$ factors of the Rietveld refinements of the XRD patterns shown in Figs. 5 and 7.

Figure 9 shows the relationship between the initiallycharged mass fraction of each sample (shown in Table 2) and the mass fractions obtained by the XRD-Rietveld method before and after the TM correction using Eq. (3) and their correction factors presented in Table 4. Figures 9(a) and 9(b) show the results for $\mathrm{Cu} K \alpha_{1}$ and $\mathrm{Co} K \alpha_{1}$ radiation, respectively. Table 6 shows the data presented in Figs. 9(a) and 9(b). The dotted lines in Figs. 9(a) and 9(b) represent a deviation of the quantitative mass fractions of \pm 3 mass $\%$. The results obtained using $\mathrm{Cu} K \alpha$ radiation without the

Table 5. $R_{\mathrm{wp}}$ and $S$ factors of the Rietveld refinement of XRD patterns shown in Figs. 5 and 7.

\begin{tabular}{ccccc}
\hline \multirow{2}{*}{ No. } & \multicolumn{2}{c}{$\mathrm{Cu} K \alpha$} & \multicolumn{2}{c}{$\mathrm{Co} K \alpha$} \\
\cline { 2 - 5 } & $R_{\mathrm{wp}}$ & $S$ & $R_{\mathrm{wp}}$ & $S$ \\
\hline 1 & 1.94 & 1.46 & 1.47 & 1.60 \\
2 & 2.03 & 1.55 & 1.34 & 1.47 \\
3 & 2.13 & 1.61 & 1.51 & 1.63 \\
4 & 2.03 & 1.55 & 1.55 & 1.68 \\
5 & 2.25 & 1.70 & 1.68 & 1.82 \\
6 & 2.26 & 1.70 & 1.65 & 1.79 \\
\hline
\end{tabular}

(a)

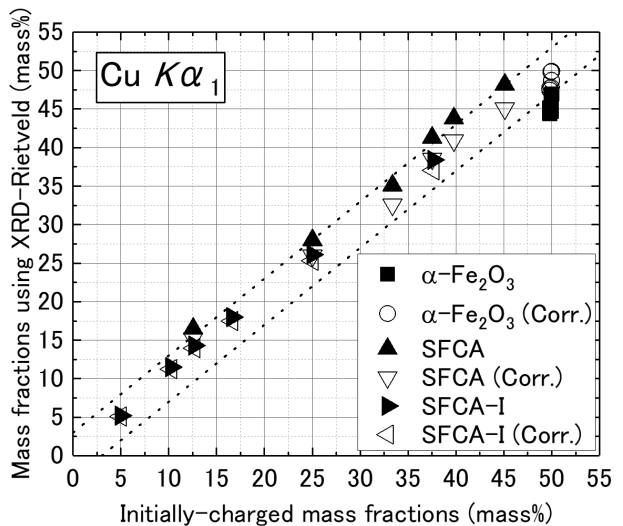

correction of the MA effect reveal that the mass fraction of $\alpha-\mathrm{Fe}_{2} \mathrm{O}_{3}$, with the largest linear absorption coefficient of $1119 \mathrm{~cm}^{-1}$ was smaller than the initially-charged mass fraction. However, each mass fraction of silico-ferrite of calcium and aluminum (SFCA, SFCA-I) with a relatively small linear absorption coefficient was greater than the initiallycharged mass fraction. The TM correction also enabled us to obtain quantitative mass fractions that were nearly identical to the initially-charged mass fractions. Furthermore, for the Co $K \alpha$ data, the mass fraction without the correction was nearly the same as the initially-charged mass fraction. Practically, no correction effect was observed, and most samples could be quantified within \pm 3 mass $\%$ because the linear absorption coefficients were small for all phases. These results confirmed that the crystalline phase in samples can be quantified with accuracy of \pm 3 mass $\%$ using the correction method developed in this study, even for measurements with $\mathrm{Cu} K \alpha$ radiation. Thus, MA affects the mass fraction of each phase but has little effect on the shape of the XRD pattern. This may be because the specimens are polycrystalline and enough fine, where a sufficiently large number of grains are observed by XRD in the cases of both small and large MA effects. This accuracy is sufficient for the use of the method for evaluation in the iron-making process and for the determination of the relationship between the mass fractions and qualities of iron sintered ores. However, two (b)

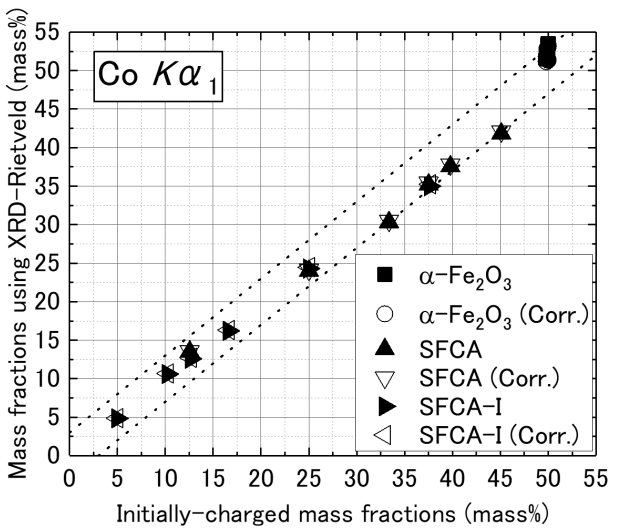

Fig. 9. Relationship between the initially-charged mass fractions of the samples (shown in Table 2) and the quantitative values obtained by the XRD-Rietveld method before and after the TM correction using Eq. (3). Figures 9(a) and 9(b) show the results obtained for the $\mathrm{Cu} K \alpha_{1}$ and $\mathrm{Co} K \alpha_{1}$ radiation sources, respectively.

Table 6. Mass fraction of each crystalline phase before and after the correction in XRD measurements of type 2 samples $\left(\alpha-\mathrm{Fe}_{2} \mathrm{O}_{3}\right.$ : H, SFCA: S0, SFCA-I: S1).

\begin{tabular}{|c|c|c|c|c|c|c|c|c|c|c|c|c|c|c|c|}
\hline & & & & \multicolumn{6}{|c|}{$\mathrm{Cu} K \alpha$} & \multicolumn{6}{|c|}{$\operatorname{Co} K \alpha$} \\
\hline & \multicolumn{3}{|c|}{$\begin{array}{l}\text { Initially-charged } \\
\text { mass fraction }\end{array}$} & \multicolumn{3}{|c|}{$\begin{array}{l}\text { Before } \\
\text { correction }\end{array}$} & \multicolumn{3}{|c|}{$\begin{array}{l}\text { After } \\
\text { correction }\end{array}$} & \multicolumn{3}{|c|}{$\begin{array}{l}\text { Before } \\
\text { correction }\end{array}$} & \multicolumn{3}{|c|}{$\begin{array}{c}\text { After } \\
\text { correction }\end{array}$} \\
\hline & $\mathrm{H}$ & S0 & S1 & $\mathrm{H}$ & S0 & $\mathrm{S} 1$ & $\mathrm{H}$ & S0 & S1 & $\mathrm{H}$ & S0 & $\mathrm{S} 1$ & $\mathrm{H}$ & S0 & S1 \\
\hline No. 1 & 50.0 & 25.0 & 25.0 & 45.9 & 28.0 & 26.1 & 48.7 & 26.0 & 25.3 & 51.7 & 24.0 & 24.3 & 51.4 & 24.2 & 24.5 \\
\hline No. 2 & 49.8 & 12.6 & 37.6 & 45.2 & 16.5 & 38.4 & 47.7 & 15.2 & 37.0 & 51.5 & 13.5 & 35.0 & 51.2 & 13.6 & 35.2 \\
\hline No. 3 & 49.8 & 37.5 & 12.7 & 44.4 & 41.3 & 14.3 & 47.5 & 38.6 & 14.0 & 52.2 & 35.2 & 12.6 & 51.8 & 35.5 & 12.7 \\
\hline No. 4 & 50.0 & 33.4 & 16.6 & 46.9 & 35.1 & 18.0 & 49.9 & 32.6 & 17.5 & 53.5 & 30.3 & 16.2 & 53.0 & 30.6 & 16.4 \\
\hline No. 5 & 50.0 & 39.8 & 10.3 & 44.7 & 43.8 & 11.5 & 47.8 & 41.0 & 11.2 & 51.8 & 37.6 & 10.6 & 51.5 & 37.8 & 10.7 \\
\hline No. 6 & 49.9 & 45.1 & 5.0 & 46.6 & 48.2 & 5.2 & 49.8 & 45.1 & 5.1 & 53.3 & 41.8 & 4.8 & 53.0 & 42.1 & 4.9 \\
\hline
\end{tabular}


additional points should be considered in the application of this technique to iron sintered ores in the industrial process. The first is the low crystallinity values of SFCA and SFCA-I in a real iron sintered ores. The second is the variation of the chemical composition in SFCA and SFCA-I that also broadens the XRD peak widths. These points make XRD peaks of SFCA and SFCA-I broader and it may be difficult to fit properly them reflecting to the mass fractions of SFCA and SFCA-I in iron sintered ores.

Based on the above-described results, for the type 2 samples, it was confirmed that the accuracy of the XRDRietveld method can be improved by the TM correction even for $\mathrm{Cu} K \alpha \mathrm{X}$-ray radiation for which the XRD-Rietveld method may not be able to determine the mass fractions with quantitative accuracy due to the MA effect.

\section{Conclusion}

We investigated the effect of the TM correction on the mass fractions of the crystalline phases of mixtures of $\alpha-\mathrm{Fe}_{2} \mathrm{O}_{3}$ and $\mathrm{ZnO}$ (type 1) and the effects of the X-ray source and the TM correction on the mass fractions of a simulated iron sintered ores samples (type 2) using the XRD-Rietveld method in experiments aimed at the application of this method in iron-making process.

For $\mathrm{Cu} K \alpha$ radiation with the energy close to that of the Fe $K$-edge absorption edge, we confirmed that the mass fractions were determined in accordance with the linear absorption coefficient of the constituent phases. In type 1 samples, when both particle sizes were sufficiently small, quantitatively accurate mass fractions were obtained as shown by the comparison to the initially-charged mass fractions. However, when the difference in particle diameters was large, quantitatively accurate mass fractions reflecting the initially-charged mass fractions of the individual crystalline phase could not be obtained. However, the mass fractions for the mixing sample were obtained using the TM correction that considers the linear absorption coefficient calculated from the chemical composition and density.

For type 2 samples, the correction method in advance of the TM correction for obtaining quantitatively accurate mass fractions of the simulated iron sintered ores was developed by considering the average particle diameter and linear absorption coefficient of the components obtained by SEM-EDS (MQA) measurements through automatic particle analysis. With this correction method, the quantitative mass fractions could be obtained to an accuracy of \pm 3 mass\% even when $\mathrm{Cu} K \alpha$ radiation was used for samples that included iron oxides. In addition, we confirmed that the mass fraction of each crystalline phase could be quantified with accuracy of \pm 3 mass $\%$ or less even without the application of the correction method when Co $K \alpha$ radiation was used. This was due to the small difference in the linear absorption coefficient between the Fe-based oxide and silico-ferrite of calcium and aluminum. Thus, our results show that even when using an X-ray source that was strongly absorbed by the samples, the correction method developed in this study can provide more accurate quanti- tative mass fractions of the individual crystal phases. It is expected that this method can be applied not only to model samples but also for industrial materials.

\section{Acknowledgments}

We thank Dr. Takafumi Takahshi, Dr. Koji Kanehashi, Dr. Kyosuke Hara, Dr. Kenichi Higuchi, Mr. Toru Takayama, Dr. Michihiro Aimoto, and Dr. Koji Saito from the Nippon Steel Corporation, Dr. Jun Okazaki from the Nippon Steel Technology Co. Ltd., Prof. Takahiro Sagawa from the Maebashi Institute of Technology, and Prof. Takashi Ida from the Nagoya Institute of Technology for useful discussions about the XRD-Rietveld method and iron sintered ores. We are also grateful to Dr. Daisuke Itabashi from the Nippon Steel Corporation for technical advice and support in conducting the SEM-EDS measurements.

\section{REFERENCES}

1) J. D. G. Hamilton, B. F. Hoskins, W. G. Mumme, W. E. Borbidge and M. A. Montague: Neues Jahrbuch Miner. Abh., 161 (1989), 1.

2) W. G. Mumme, J. M. F. Clout and R. W. Gable: Neues Jahrb. Miner. Abh., 173 (1998), 93. https://doi.org/10.1127/njma/173/1998/93

3) Y. Hida, J. Okazaki, K. Itoh and M. Sasaki: Tetsu-to-Hagané, 73 (1987), 1893 (in Japanese). https://doi.org/10.2355/ tetsutohagane1955.73.15 1893

4) L. X. Yang and C. E. Loo: ISIJ Int., 37 (1997), 449. https://doi. org/10.2355/isijinternational.37.1057

5) F. Zhang, S. An, G. Luo and Y. Wang: J. Iron Steel Res. Int., 19 (2012), No. 4, 1

6) F. Shen, G. Li, Z. Ding and L. Mu: J. Iron Steel Res. Int., 16 (2009), No. 3, 1. https://doi.org/10.1016/S1006-706X(09)60035-2

7) I. Tonžetić and A. Dippenaar: Miner. Eng., 24 (2011), 1258. https:// doi.org/10.1016/j.mineng.2014.03.007

8) H. M. Rietveld: J. Appl. Crystallogr., 2 (1969), 65. https://doi. org/10.1107/S0021889869006558

9) R. J. Hill and C. J. Howard: J. Appl. Crystallogr., 20 (1987), 467. https://doi.org/10.1107/S0021889887086199

10) F. Izumi and K. Momma: Solid State Phenom., 130 (2007), 15. https://doi.org/10.4028/www.scientific.net/SSP.130.15

11) N. Doebelin and R. Kleeberg: J. Appl. Crystallogr., 48 (2015), 1573. https://doi.org/10.1107/S1600576715014685

12) L. Lutterotti, S. Matthies, H.-R. Wenk, A. S. Schultz and J. Richardson: J. Appl. Phys, 81 (1997), 594. https://doi.org/10.1063/1.364220

13) T. Degen, M. Sadki, E. Bron, U. König and G. Nénert: Powder Diffr., 29 (2014), Suppl. S2, S13

14) J. C. Taylor: Powder Diffr., 6 (1991), 2. https://doi.org/10.1017/ S0885715600016778

15) S. Ichikawa, D. Fujimura, A. Ohbuchi and T. Nakamura: ISIJ Int., 56 (2016), 2228. https://doi.org/10.2355/isijinternational.ISIJINT-2016-392

16) T. Takayama, R. Murao and M. Kimura: ISIJ Int., 58 (2018), 1069. https://doi.org/10.2355/isijinternational.ISIJINT-2017-717

17) L. Alexander and H. P. Klug: Anal. Chem., 20 (1948), 886. https:// doi.org/10.1021/ac60022a002

18) J. Als-Nielsen and D. McMorrow: Elements of Modern X-ray Physics, 2nd ed., John Wiley and Sons, Hoboken, NJ, (2011), 18.

19) G. W. Brindley: Lond. Edinb. Dublin Philos. Mag. J. Sci., 36 (1945), 347. https://doi.org/10.1080/14786444508520918

20) J. C. Taylor and C. E. Matulis: J. Appl. Crystallogr., 24 (1991), 14. https://doi.org/10.1107/S002188989000841X

21) N. V. Y. Scarlett and L. C. Madsen: Powder Diffr., 33 (2018), 26. https://doi.org/10.1017/S0885715618000052

22) R. S. Winburn, D. G. Grier, G. J. McCarthy and R. B. Peterson: Powder Diffr. 15 (2000), 163. http://doi.org/10.1017/S0885715600011015

23) R. S. Winburn, S. L. Lerach, B. R. Jarabek, M. Wisdom, D. G. Grier and G. J. McCarthy: Adv. X-ray Anal., 42 (1998), 387.

24) I. C. Madsen, N. V. Y. Scarlett, L. M. D. Cranswick and T. Lwin: J. Appl. Crystallogr., 34 (2001), 409. https://doi.org/10.1107/ S0021889801007476

25) B. M. Pederson, K. J. Schaible and R. S. Winburn: Adv. X-ray Anal., 47 (2003), 200.

26) D. Nie, T. Xue, Y. Zhang and X. Li: Sci. China Ser. B Chem., 51 (2008), 823. https://doi:10.1007/s11426-008-0061-0

27) J. Albertsson, S. C. Abrahams and Å. Kvick: Acta Crystallogr. B, 45 (1989), 34. https://doi.org/10.1107/S0108768188010109 